\title{
A Lesson on Social Role Theory: An Example of Human Behavior in the Social Environment Theory
}

\author{
Agnes M. Dulin
}

\begin{abstract}
This paper discusses the social role theory, a theory of Human Behavior in the Social Environment (HBSE). Relevance of this topic is briefly discussed, as well as a definition of the theory and its historical background. Empirical research that employs this theory will be discussed. Recommendations will be made for future theory development and implications for social work education will conclude the discussion.
\end{abstract}

Keywords: Social role theory, gender roles, gender stereotypes

$\mathrm{H}$

uman Behavior in the Social Environment (HSBE) is part of the foundation curriculum for Social Work Education, according to The Council on Social Work Education (CSWE) (2004). According to the Accreditation and Policy Standards, "Content includes empirically based theories and knowledge that focuses on the interactions between and among individuals, groups, societies, and economic systems. It includes theories and knowledge of biological, sociological, cultural, psychological, and spiritual development across the life span: the range of social systems in which people live, and the ways social systems promote or deter people in maintaining or achieving health and well-being" (p. 9).

Social Role Theory appears to fit nicely with the description of HBSE, in that it is a theory that focuses on interactions between and among individuals, groups, societies, and economic systems as developed by social systems in which people live. At times, these social systems sometimes promote or deter certain people in maintaining or achieving health and well-being. This paper will attempt to demonstrate how Social Role Theory is appropriate to study in HBSE courses.

Historically, Social Role Theory developed during the 1980s as a genderrelated theory. Earlier studies in the 1970s that covered differences between the sexes had been strongly criticized and progress on the topic was slow. Since the 1980s, Eagly has devoted considerable time to this topic and has published a book in 1987 on the theory: Sex Differences in Social Behavior: a Social Role Interpretation. Although earlier research had been conducted on

Agnes M. Dulin, LMSW, is a doctoral student, University of Houston, Houston, TX 77204-4013.

Copyright $^{\circ} 2007$ Advances in Social Work Vol. 8 No. 1 (Spring 2007) 104-112. Indiana University School of Social Work. 
sex differences, most had focused on areas, including biological differences and early childhood socialization. Eagly thought that "Explanations based on the social roles that regulate behavior in adult life" (p. 4) had not been explored and proceeded to show how a theory of sex-typed behavior could explain differences in men and women.

At this point, some definitions, as defined by Eagly, are needed in order to better understand her theory and reasoning. The term sex is defined, based on biology, as grouping of humans into two categories: male and female. Gender is described as meanings that people and society in general assign to female and male categories. Eagly used gender roles as a term for the social roles that a society designates to men and women. Gender stereotypes are stereotypes that people believe about men and women. Sex differences, as defined by some psychologists, make up biological differences, and gender differences embody environmental differences. However, Eagly used the term sex differences to denote the differences between males and females on several measures, not just biology. Her intent was mostly social psychological, but, at the same time, did not want to exclude biology entirely, since there is no clear consensus on the causes of differences between the sexes.

Eagly set out to determine whether biology or society determined our behaviors; the same old question: nature or nurture. Her thesis was that, "The contemporaneous influences arising from adult social roles are more directly relevant to sex differences in adult social behavior than is prior socialization or biology" (1987, p. 9). What she found was that there was not necessarily an either/or answer but determined that sex roles or social roles are indeed influenced by the society in which we live.

Social Role Theory uses a structural approach to sex differences, rather than a cultural approach, in that structural pressures (family, organizations, and communities) have caused men and women to behave in different ways. The perception is that people have a social role based solely on their gender. These stereotypic gender roles are formed by social norms that apply to people of a certain category or social position. Social norms, according to social psychologists, are shared expectations about appropriate qualities or behaviors (Eagly, 1987, p. 13). According to Eagly, "Social Role Theory of sex differences promotes a view of social life as fundamentally gendered, given current social arrangements" (p. 31). In other words, society has shared expectations about women, and these expectations form female gender roles, and shared expectations about men form male gender roles. Surprisingly, people tend to do what is expected of them or act the way that these roles imply and, as a result, men and women learn different skills, thus perpetuating sex differences.

Gender roles are more general and encompass a greater scope of definition of male and female roles. In contrast, social roles are more specific to roles in family and work life. Eagly believed that social roles guide our behaviors more than the gender we inhabit.

Earlier research has shown that most beliefs about the differences between men and women can be divided into two dimensions: communal and agen- 
tic. The definitions of these dimensions, preferred by Eagly, were actually originated by Bakan (1966). Agentic qualities are manifested by self-assertion, self-expansion, and the urge to master. Agentic qualities are attributed to males more than females. Communal qualities are manifested by selflessness, concern for others, and a desire to be at one with others. In contrast, these qualities are attributed to females more than males. Eagly used these dimensions to differentiate between males and females in work and family life.

Eagly proposed that division of labor was the culprit that designated the differences between males and females. Division of labor induces gender role expectations and sex-typed skills and beliefs, therefore, producing sex differences in social behavior. For example, young people learn and emulate the roles they see played out by the adults in their lives. They deduce that males are more agentic and females are more communal and, in order to be successful, each conforms to the appropriate roles. Social roles are dictated by division of labor, and gender roles tend to reinforce the status quo. Eagly and Steffen (1984) tested the correlation between gender stereotype and division of labor and found that occupational role was a strong determinant of judgments of communal and agentic qualities. Results indicated that, when people did not know the job status (employee or homemaker), women were perceived as more communal and men as more agentic. However, when job status was known, employed men and women were perceived as more agentic and homemakers, both male and female, were perceived as communal. So, those who are in domestic roles were rated as more communal and less agentic than those in the employee role. With more and more women in the labor market since the 1970s and the feminist movement, it is surprising that studies continue to show that there is a tendency to view women with communal qualities and males with agentic qualities (Eagly \& Steffen, 1984).

Conway, Pizzamiglio, and Mount (1996) conducted research to test Eagly and Steffen's study, comparing job status with agency and communality. They found that low status individuals were rated as more communal than agentic and high status individuals were rated as more agentic than communal, regardless of sex or occupation. These findings imply that communal, which is normally associated with females, is associated with low status positions, so that females are associated with low status jobs. The same implication represents males having agentic qualities, therefore, having high status positions.

To test her theory further, Eagly and her colleagues conducted research on aggression and helping behavior using Social Role Theory. Eagly and Steffen (1986) conducted extensive research on aggression by using meta-analysis and found that men are more aggressive than women and that the difference is greater for physical than psychological aggression. Results also indicated that men and women think differently about aggression, and this difference could be an important mediator in studying aggression.

Eagly and Crowley (1986) conducted a meta analysis to determine whether there were sex differences in helping behavior. Ways of defining "helping behavior" for women, according to Social Role Theory, was, for example, caring for the personal and emotional needs of others and helping others to 
attain their goals. Ways of defining this behavior for men, according to Social Role Theory, might be heroic behavior, altruistic acts that may save others but put their own safety at risk. However, most research conducted on helping has been geared toward the male definition of helping and, as a result, the analysis did determine that men are more helpful than women. Eagly suggested more research using other definitions of helping to produce more valid outcomes.

More currently, Eagly and Johannesen-Schimidt (2001) presented new data concerning transformational, transactional, and laissez-faire leadership styles using meta-analysis and the framework of Social Role Theory. Transformational style includes motivating workers to feel respect and pride, because of their association with the leader. Transactional style includes strategies of rewards and self-interests, while laissez-faire style uses a passive form of management until there is a problem. Results indicated that leadership style findings from experimental settings tend to be gender-stereotypic. Female leaders exceeded male leaders on the female-stereotypic transformational dimensions of motivating their workers to feel respect and pride because of their association with them, showing optimism and excitement about future goals, and tending to mentor and attend to individual needs. Females also exceeded males in the transactional dimension of contingent rewards. However, male leaders exceeded females on active and passive management-by-exception and laissez-faire styles, which means that males tend to pay attention to workers' problems and mistakes, wait until problems become severe before attempting to solve them, and become absent and uninvolved at critical times. The authors indicated that the greater effectiveness of females reflected the negative relationships of the passive management-by-exception and laissez-faire styles to the positive relationships of transformational and contingent reward styles.

Eagly, Karua, and Makhijani (1995) conducted an extensive meta-analysis on gender and the effectiveness of leaders. They found that, generally, male and female leaders were equally effective, which can be interpreted as a good thing. However, there was evidence that showed that male leaders were rated as more effective than females when the leadership role was defined in masculine terms, such as ability to direct and control people, and women were more effective when the roles were defined in less masculine roles, such as ability to get along with other people.

Eagly's research on Social Role Theory implies that conformity to genderrole expectations is a major source of the sexes' differing behavior (1987, p. 126). Eagly's intent was to introduce another facet to the mystery surrounding sex differences, to narrow the idea to a simple idea so that it would be possible to produce a "Coherent conceptual representation" (p. 4) of a theory about sex differences. Eagly intended, not so much to solve the mystery, but to open up another avenue for study on this topic. She hoped that the theory would induce others to test the theory; upholding her beliefs or dispelling them, she did not care. Her goal was to increase the knowledge of sex-typed behavior, using this theory and other interrelated theories. 
An outcome of the social role theory is that social roles appear to be dynamic, which is encouraging for men and women alike. Diekman, Goodfriend, and Goodwin (2004), using Social Role Theory, tested whether gender stereotypes are dynamic in that, as women progress in the work world, certain stereotypes disappear or change. This study examined whether this dynamic aspect of gender stereotypes extends to beliefs about power, or whether the gender power hierarchy is perceived as being relatively immutable. The first study examined participants' beliefs about the power of men and women in the future. The majority of participants $(98 \%)$ predicted that women would gain power by the year 2050. About half predicted that men's power would stabilize, and $45 \%$ predicted a decrease in power for men. The second study examined the relative gains or losses in power and explored the relationships among perceived power, perceived social roles of men and women, and gender stereotypes. The second study found that male power would decrease only relationally and would maintain power in other areas, such as economic, political, and occupational. The authors also perceived that women would gain in individual and relational power more than economic, political, and occupational power. It appears that stereotypes can be dynamic.

Others have conducted considerable research using Social Role Theory as a theoretical framework. For instance, Forsyth, Heiney, and Wright (1997) predicted that conservative subordinates would be less satisfied with a woman leader, regardless of her leadership style, compared to liberal subordinates. Results support Eagly's analysis that, those who possessed more traditional stereotypes about women, judged women more harshly than individuals whose attitudes about women were less stereotypical. Social Role Theory proposes that women in leadership roles face a dilemma in that, when they are effective leaders, they are judged more harshly and are usually evaluated more negatively than men in the same roles.

Another work-related study by Fuegen, Biernat, Haines, and Deaux (2004) used Social Role Theory to predict that the parenting role, rather than gender, would determine how parents are judged. They set out to determine the influence of gender and parental status on employment decisions. Participants evaluated applicants for a job, some being female, male, married, or single. They found that parents were judged less agentic and less committed to employment than non-parents, and those who were male parents were given more slack than female parents and childless males.

Franke, Crown, and Spake (1997) used meta-analysis to investigate the role gender plays in the perceptions of ethical decision-making and used Social Role Theory to rationalize gender differences. The authors predicted significant gender differences in the perceptions of what constituted ethical business practices, but these differences would decline with work experience. They found that differences were smaller in samples of individuals with more work experience. However, on average, women show higher ethical standards than men.

Harrison and Lynch (2005) used the theory to test several hypotheses concerning gender role and athletics. The first hypothesis predicted that an ath- 
lete's gender would not singularly influence perceptions of agency and communality. The findings indicated that there were no significant differences in perceived agency and communality of both females and males. The second hypothesis predicted that the type of sport would singularly influence the perceptions of agency and communality because of the influence of athletic roles. Findings indicated that, for the communality index, there was a significant effect on the type of sport. An example being that cheerleaders were higher in communality than football players. The third hypothesis predicted that perceptions of agency and communality would be mutually influenced by an athlete's gender and the type of sport. Findings indicated that males and cheerleaders were high in communality, but the type of sport of females did not influence perceived communality. The fourth hypothesis predicted that there would be higher rates of approval for those who played gendered traditional sports. Findings indicated higher rates of approval for females who played in male-dominated sports. However, approval rates for males were the same for masculine and feminine type sports. The research consistently supported social role theory, that an athlete's gender did not significantly affect global perceptions of gender role orientation.

In their study, Vogel, Wester, Heesacke, and Madon (2003) proposed that emotional vulnerability causes people who are involved in close relationships to adhere to gender roles. Previous research had been conducted using participants who were not acquainted. The initial results of this study were consistent with the hypothesis. Women's behaviors stayed consistent, whereas, men exhibited fewer emotionally restrictive behaviors and more withdrawal behaviors when they talked about emotionally difficult topics, which would be consistent with Social Role Theory.

As demonstrated above, Social Role Theory has been used in theoretical frameworks for studies about sex differences addressing various issues, such as aggression, helping behaviors, the dynamics of stereotypes, leadership styles, attitudes and effectiveness, parenting, ethical decision-making, athletics, and emotional vulnerability. Most of the research upholds the theory's premise that, in certain social situations, males and females act according to the social norms that originate from a division of labor at work and in the home.

However, with any theory, there is always criticism. Archer (1996) examined Social Role Theory and evolutionary theory as explanations for sex differences. Evolutionary theory attributes most sex differences to the consequences of sexual selection and the conflict that arises with the different reproductive strategies of the sexes. Remember that Social Role Theory attributes the division of labor to sex differences. Archer concluded that, since evolutionary theory could explain other mammals' sex differences, that it was a better explanation. Eagly (1997) gave a rebuttal to Archer's criticism of Social Role Theory, stating that she never intended for the theory to be an ultimate answer to the puzzle of sex differences. Instead, she defended her theory as one of many interrelated theories that, "Social scientists have provided [as] an array of interrelated theories, each of which illuminates certain aspects of the 
complex of psychological and social processes by which gendered behavior is produced" (p. 1382). Eagly intended for her theory to be used in conjunction with other theories to better understand the intricacies of males and females.

Several limitations exist concerning Social Role Theory. One limitation suggested by Eagly was that none of the research that she analyzed about sex differences was done in natural settings, and outcomes might have been different. Eagly suggested that further research be conducted in more natural settings so that males and females have the advantage of being in their natural roles. How people react to real life situations can be very different from controlled situations or when they are completing surveys.

Another limitation to Eagly's early research was the way in which she conducted the research, which was by using meta-analysis. There is always the effect-size dilemma of what size is considered to be effective. Although Eagly was able to review numerous studies on the various topics, there was usually considerable disparity between the outcomes, causing effect size to be less significant. However, more recent research has entailed other forms of statistical analysis.

A third limitation with the theory itself may be that it may not be as relevant to today's culture. Monk-Turner et al. (2002) conducted a study on altruistic behavior and found no differences between men and women. They suggested that, possibly Social Role Theory is not as relevant as it was in the 1980s, when Eagly formulated the theory in that gender roles are not as pronounced or defined as 20 years ago. This suggestion is strengthened by the study conducted by Diekman, Goodfriend, and Goodwin (2004) on the dynamics of gender stereotypes, which was discussed earlier.

The next steps for theory progression involve continuing to use it as a theory of sex differences, along with other interrelated theories, to help explain why and what the differences are. As we better learn the differences, then it is possible that conditions and expectations of certain roles will be defined in agentic and communal ways, not exclusively, but inclusively. This knowledge can add to equalizing opportunities for men and women, alike. An important tactic to strengthen Social Role Theory would be to find better measurements of constructs, such as aggression, helping behavior, and others that are difficult to measure accurately for both males and females. The research would be more salient if instruments measured what they were intended to measure.

Implications for social work education are positive, in that as we learn more about the differences between men and women, we will inadvertently discover more similarities than differences. In working with our clients, just being aware of expected social roles within their environment may help us to work more effectively with them. Being cognizant that stereotypes and social roles are powerful tools that most people tend to conform to, whether they realize it or not, is pertinent to all aspects of our lives-our families, our work, and our community.

The most powerful tool of this theory is to help us know there should be a continuum of role styles. Until we get away from agentic equaling masculine 
and communal equaling female and lean more towards a continuum of agency to communality, stereotypes will not lessen or diminish. As seen in the research by Conway, Pizzamiglio, and Mount (1996), communal qualities are perceived to be characteristic of low status jobs. In other words, there cannot be a continuum if one dimension is perceived as better than another. It is important for social work educators to continue to stress the importance of using communal and agentic qualities in social work. Educators should help students find their own style so they can use it as a strength to better serve clients and manage agencies.

\section{References.}

Archer, J. (1996). Sex differences in social behavior: Are the social role and evolutionary explanations compatible? American Psychologist, 51(9), 909-917.

Archer, J. (1997). On the origins of sex differences in social behaviors: Darwinian and non-Darwinian accounts. American Psychologist, December, 1383-1385.

Bakan, D. (1966). The duality of human existence: An essay on psychology and religion. Chicago: Rand McNally.

Conway, M., Pizzamiglio, M.T., \& Mount, L. (1996). Status, communality and agency: Implications for stereotypes of gender and other groups. Journal of Personality and Social Psychology, 71(1), 25-38.

Council on Social Work Education (CSWE) (2004). Educational Policy and Accreditation Standards. http://www.cswe.org.

Diekman, A.B., Goodfriend, W., \& Goodwin, S. (2004). Dynamic stereotypes of power: Perceived change and stability in gender hierarchies. Sex Roles, 50(3/4), 201-215.

Eagly, A.H. (1987). Sex differences in social behavior: A social-role interpretation. Lawrence Erlbaum Associates: Hillsdale.

Eagly, A.H. (1997). Sex differences in social behavior: Comparing social role theory and evolutionary psychology. American Psychologist, December, 1380-1383.

Eagly, A.H., \& Crowley, M. (1986). Gender and helping behavior: A meta-analytic review of the social psychological literature. Psychological Bulletin, 100, 283-308.

Eagly, A.H., \& Johannesen-Schimidt, M.C. (2001). The leadership styles of women and men. Journal of Social Issues, 57(4), 781-797.

Eagly, A.H., Karau, S.J., \& Makhijani, M.G. (1995). Gender and the effectiveness of leaders: A meta-analysis. Psychological Bulletin, 117(1), 125-145.

Eagly, A.H., \& Steffen, V.J. (1986). Gender and aggressive behavior: A meta-analytic review of the social psychological literature. In A.H. Eagly, Sex differences in social behavior: A social role interpretation (128-135). Lawrence Erlbaum Associates: Hillsdale.

Eagly, A.H., \& Steffen, V.J. (1984). Gender stereotypes stem from the distribution of women and men into social roles. In A.H. Eagly, Sex differences in social behavior: A social role interpretation (pp. 70-95) Lawrence Erlbaum Associates: Hillsdale.

Forsyth, D.R., Heiney, M.M., \& Wright S.S. (1997). Biases in appraisals of women leaders. Group Dynamics: Theory, Research, and Practice, 1(1), 98-103.

Franke, G.R., Crown, D.F., \& Spake, D.F. (1997). Gender differences in ethical perceptions of business practices: A social role theory perspective. Journal of Applied Psychology, 82(6), 920-934.

Fuegen, K., Biernat, M., Haines, E., \& Deaux, K. (2004). Mothers and fathers in the workplace: How gender and parental status influence judgments of job-related competence. Journal of Social Issues, 60(4), 737-754. 
Harrison, L.A, \& Lynch, A.B. (2005). Social role theory and the perceived gender role orientation of athletes. Sex Roles, 52(3/4), 227-236.

Monk-Turner, E., Blake, V., Chniel, F, Forbes, S., Lensey, L., \& Madzuma, J. (2002). Helping hands: A study of altruistic behavior. Gender Issues, Fall, 65-70.

Vogel, D.L., Wester, S.R., Heesacke, M., \& Madon, S. (2003). Confirming gender stereotypes: A social role perspective. Sex Roles, 48(11/12), 519-528.

\section{Author's Note:}

Address correspondence to: Agnes M. Dulin, LMSW, doctoral student, University of Houston, 237 Social Work Building, Houston, TX 77204-4013, USA. e-mail: agnes.dulin@mail.uh.edu. 